\title{
A Constituição de 1937 e a lei número 62, de 1935
}

Cesarino Junior

Sumario - 1 - Posição do problema. 2 - A tese da auto-aplicabilidade. 3 - A tese da normatividade. 4 - Nossa opinião. 5 - Seu desenvolvimento. $6-$ Ad impossibilia nemo tenetur. $7-0$ factum principis, como caso de força maior.

1 - A Constituição de 10 de novembro de 1937, no art. 137, letra $f$, determina: "A legislação do trabalho observará, alem de outros, os seguintes preceitos: nas empresas de trabalho continuo, a cessação das relações de trabalho, a que o trabalhador não haja dado motivo, e quando a lei não lhe garanta a estabilidade no emprego, cria-lhe o direito a uma indenização proporcional aos anos de serviço"

Este dispositivo constitucional deu lugar a uma grande celeuma, ainda não aplacada. O Consultor Juridico do Ministerio do Trabalho, Prof. Oliveira Viana, levantou a tése de que, sendo o preceito constitucional auto-aplicavel, estavam ipso facto, revogados os $\S \S 1 .^{\circ}$ e $2 .^{\circ}$, do art. $5 .^{\circ}$, da Lei n. ${ }^{\circ}$, de 5 de junho de 1935 , que dispunham: "Considera-se tambem causa de fôrça maior para o efeito de dispensa do empregado, a supressão do emprego ou cargo, por motivo de economia aconselhada pelas condições economicas e financeiras do empregador e determinada pela diminuição de negocios e restrição da atividade comercial"; e: "Considerase provada a fôrça maior, quando se tratar de uma providencia de ordem geral que atinja todos os empregados e na mesma proporção dos vencimentos de cada um ou se caracterize pelo fechamento de um estabelecimento ou filial, em 
relação aos empregados destes, ou supressão de um determinado ramo de negocios" Esta tése provocou forte reação nos meios patronais profundamente atingidos por ela. Nestas condições resolveu o Sr. Ministro do Trabalho ouvir o Sr. Consultor Geral da Republica, então o Prof. Anibal Freire, cujas conclusões foram favoraveis á opinião do Prof. OLIvEIRA VIANA. A jurisprudencia, até agora, só se manifestou sobre o caso em dois acordãos do Tribunal de Apelação do Distrito Federal, sendo o primeiro deles, relatado pelo Sr. Desembargador Candido Loвo, que concluiu em sentido contrario ao dos referidos pareceres, afirmando que o preceito constitucional é meramente normativo e assim a sua plena vigencia depende de sua transcrição em lei ordinaria.

Assim posto o problema, vê-se que a principal questão a resolver é a de saber si o preceito da letra $f$, do art. 137, da Constituição, é auto-aplicavel ou normativo. Examinemos as duas téses opostas.

2 - Os partidarios da revogação entendem que: "sendo a Constituição a lei suprema do paiz, de modo que contra a sua letra ou espirito não prevalecem resoluções dos poderes federais, constituições, decretos ou sentenças estaduais, nem tratados ou quaisquer atos diplomaticos" (1), o preceito constitucional revogou os citados $\S \S 1 .^{\circ}$ e $2 .^{\circ}$, do art. $5 .^{\circ}$ da lei $n .^{\circ} 62$, por isso que êles desnaturavam o conceito de fôrça maior. Assim se exprime o Sr. Consultor Geral da Republica: "O que, ao meu vêr, o legislador quiz proscrever foram as ampliações abusivas e desvirtuadoras da conceituação juridica da fôrça maior, colocando o empregado a salvo de quaisquèr maquinações ou embustes. (2) Da mes-: ma opinião é o Dr.' Mario Guimarães de Souza, em cuja solida argumentação se baseou o Sr. Consultor Geral da Re-

(1) Tücker, The Constitution of the United States, 1889, voI. I. pg. 375/376, apud Carlos Maximiliano, Hermeneutica e Aplicação do Direito, à pg. 320. pg. 95 .

(2) Parecer citado in "Revista Forense" Rio, 1940, vol. 81 , 
publica (3): “A lei n. ${ }^{\circ} 62$, violentou o direito, desnaturando o conceito classico da fôrça maior, quando considera como tal uma deliberação voluntaria do patrão, sem o carater de inevitabilidade, seu elemento essencial, de suprimir o emprego, por simples motivo de economia, embora aconselhada pelas suas condições economicas e financeiras ou mesmo uma providencia de ordem geral, como o fechamento do estabelecimento ou filial"

3 - Por sua vez, os defensores da tése oposta afirmam com o Sr. Desembargador Candido Loвo: "O referido art. 137, letra $f$, da Constituição de 1937, não firma outra cousa senão "um direito a uma indenização", porem a letra $f$, só pode e só deve ser interpretada rigorosamente de acordo com o art. 137, de que faz parte e que diz claramente: "a legislação do trabalh') observará, alem de outros, os seguintes preceitos", logo, necessario se torna que a legislação do trabalho posterior a novembro de 1937 contenha um dispositivo regulando a materia, em principio, em tése, preliminarmente creada e tanto que foi o proprio texto constitucional que empregou a palavra "observará", o que demonstra que seria feita uma lei propria regulamentando o assunto, isto é, "o direito a uma indenização proporcional aos anos de serviço" e tambem "cria-lhe o direito", palavras essas que isoladas ou conjugadas só podem ser interpretadas como uma garantia patrimonial que será observada por lei futura" E ainda: "De resto, o art. 139, da Constituição de 1937, prometeu uma legislação social que certamente virá regular e dirimir "os conflitos oriundos das relações entre empregadores e empregados que será regulada em lei”. Ora, que quer isto dizer? Precisamente o que vem de ser demonstrado: a letra $f$, do art. 137, da Constituição de 1937 creou um direito a ser regulado por lei futura, que observará os

(3) A indenização de antiguidade e a Constituição de 1937, Recife, 1938, pg. 36, apud Arlindo Figueiredo, Legislaçâo do Trabalho, Recife, 1939, pg. 14. Cf. do mesmo autor a Indenizaçẫo de Antiguidade na Falencia do Empregador, in "Revista do Trabalho", de Junho de 1938, pg. 243. 
preceitos da legislação social" E ainda: "Pensar de outro modo é atribuir ao legislador de 10 de novembro uma intenção que êle não teve, qual a de fixar na Constituição não só os principios e as téses para serem regulamentados por lei ordinaria, como tambem as normas processuais norteadoras desses mesmos principios e téses, , o que constitue absurdo, maximé em face do artigo 139" (4) Identica afirmação fez o Sr. Desembargador Frederico Sussekind: “ .êsse dispositivo constitucional, que depende de lei ordinaria para poder vigorar" (5).

Por sua vez afirma Oliveira Filho: "Considerando, pois, que por se ter fechado certa filial, onde trabalhavam empregados, cessaram as relações de trabalho entre êstes e o empregador; considerando que a lei n. 62 , de 1935 , isenta o empregador de qualquer responsabilidade quando se fecha a filial, $\S 2 .^{\circ}$, do art. 5 , que é caso de cessação de trabalho, e não de despedida injusta; considerando que a Constituição de 1937 por sua vez não impoz ao empregador qualquer obrigação de indenizar no caso em que cessasse o trabalho pelo fechamento da filial, antes, o que existe é o $\S 2 .^{\circ}$, da lei 62 , isentando dessa indenização o empregador; por certo que subsiste a isenção de indenizar constante do $\S 2 .^{\circ}$, art. $5 .^{\circ}$, da lei $n .^{\circ} 62$, até que uma lei ordinaria venha imputar na pessoa do empregador a indenização que a letra " $f$ ", artigo 137, da Constituição Federal, crearam em beneficio do empregado" (6).

Canavarro Pereira invoca em defesa do mesmo ponto de vista os acordãos do Supremo Tribunal Federal, de 24 de maio e de 12 de julho de 1938, que, embora não se referindo expressamente á questão, aplicaram os dispositivos dos $\S \S 1 .^{\circ}$ e $2 .^{\circ}$ da lei $n .^{\circ} 62$, em plena vigencia da Constitui-

(4) In acordão do Tribunal de Apelação do Distrito Federal, de $11 / 9 / 39$, na "Revista do Trabalho", Rio, 1939, pgs. 460 e 461 .

(5) Acordão do mesmo Tribunal, de 16/7/40, em I. A. P. C., n. de agosto de 1940 , pg. 60 .

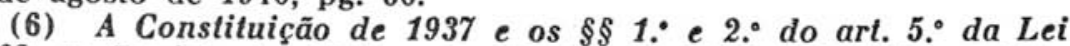
n..$^{\circ}$, na Revista dos Tribunais, São Paulo, 1940, vol. 124, pg. 415, e in Legislação do Trabalho, de janeiro de 1940, pg. 12. 
ção de 1937. (7) Ainda recentemente, em acordão de 6 de julho de 1939, decidiu a Suprema Corte no mesmo sentido (8).

Ainda nesta corrente, afirma Epaminondas de Carval ho: "Sustentamos que não revogou porque, sendo um preceito normativo, unicamente estabeleceu principios e téses para serem regulados em lei ordinaria. Por outro lado, o direito creado só será definido, regulamentado, pela lei futura interpretadora do preceito constitucional. Tanto isso é verdade, que o proprio texto invocado, empregou a palavra "observará" o que indica claramente a necessidade da elaboração de uma lei reguladora do assunto"

4 - Expostos assim os argumentos de um lado e de outro, enunciemos a nossa opinião. Ela já constava de livro nosso: "Estas duas hipoteses, previstas nos $\S \S 10^{\circ}$ e $2 .^{\circ}$, do citado artigo $5 .^{\circ}$, foram afastadas pelo parecer do Sr. Consultor Geral da Republica, largamente publicado, que as considerou como revogadas pelo dispositivo constitucional a que nos vimos referindo. Não ha duvida de que a bôa doutrina está com o parecer, uma vez que nessas hipoteses, principalmente tendo em vista o disposto no $\S 2 .^{\circ}$ citado, não se verifica geralmente obstaculo irremovivel que caracterize o que juridicamente se chama de "fôrça maior" Entretanto, mesmo nesses casos pode ela ocorrer, e então desaparecerá a responsabilidade do empregador" (10).

5 - Entretanto, como então não pudemos desenvolver esse nosso ponto de vista, "brevitatis causa", vamos fazê-lo aqui, examinando as opiniões expostas nos parágrafos anteriores, a começar pela segunda.

(7) Concordata de Empresa Empregadora, na Revista do Trabalho, Rio, 1940, pg. 23/24. Vêr o acordão de 12 de julho de 1938, na revista Legislação do Trabalho, de 1939, pg. 17.

(8) In Revista do Trabalho, n. ${ }^{\circ}$ de abril de 1940, pg. 169.

(9) Restrição da Universalidade do Juizo da Falencia, in Revista do Trabalho, n. de maio de 1940, pg. 221.

(10) Citado Direito Social Brasileiro, pg. 441. Cf. nota 18 deste parecer. 
Pontes de Miranda, sem duvida um dos nossos maiores jurisconsultos, define: "Quando uma regra se basta por si mesma para sua incidencia, diz-se bastante em si, self-executing, self-acting, self-enforcing. Quando, porém, precisam as regras juridicas de regulamentação, porque, sem a creação de novas regras juridicas que as completem, ou suplementem, não poderiam decidir, e, pois, ser aplicadas, dizem-se não bastantes em si" (11). De notar que o eminente Mestre não atribue importancia á classificação das regras juridicas como "programaticas", isto é, as regras por êle definidas: "aquelas em que o legislador, constituinte ou nã̃o, em vez de editar uma norma de aplicação concreta, apenas traça linhas diretoras, pelas quais se hão de orientar os Poderes Publicos" Com efeito é ele mesmo quem afirma, eodem loco: "Rigorosamente, o que se deve ter em vista é a dicotomia das regras juridicas em regras bastantes em si e em regras não bastantes em sî; porque tanto umas quanto outras, podem ser simplesmente programaticas"

Ora, dadas estas definições, assiste razão ao Sr. Desembargador CANDIDO LoBo em considerar apenas normativa a regra da Constituição? Quer parecer-nos, data venia, que S. Excia., esquecido das modernas escolas de interpretação das leis, dá exagerada e indevida importancia ás palavras da lei, sendo assim conduzido a afirmações que, levadas á suas ultimas consequencias, importariam em nada menos que negar-se a existencia de toda a legislação social anterior á Constituição de 1937 !

Mas, não pode ser̉ assim. E' preciso lembrar a lição do Sr. Ministro Carlos Maximiliano: "Devem as instituições ser entendidas e postas em função, de modo que correspondam ás necessidades politicas, ás tendencias gerais da nacionalidade, á coordenação dos anhelos elevados e justas aspirações do povo" (12). A expressão "observará" do caput do art. 137, da Constituição, assim como a referencia á "legis-

(11) Comentarios á Constituição Federal de 10 de novembro de 1937, Rio, 1938, vol. I, pg. 79.

(12) Ob. cit., pg. 310. 
lação social", do seu art. 139, evidentemente não podem significar que toda a legislação social tenha que ser decretada após 10 de novembro para ter vigencia. Não é mais curial a interpretação de que o citado artigo 137 , combinado com o artigo 183, revalida toda a legislação anterior a eles, desde que "explicita ou implicitamente não contrariem as disposições desta Constituição"? Porventura, não estarão em vigor as centenas de leis sociais absolutamente conformes aos itens do art. 137, só porque não foram promulgadas após 10 de novembro de 1937 ? E, ao contrario, não estarão revogadas, no todo ou em parte, as poucas leis sociais explicita ou implicitamente contrarias aos mesmos preceitos?

A esta ultima pergunta o Supremo Tribunal Federal respondeu afirmativamente ao resolver sobre a validade da exigencia feita pelo decreto $n .^{\circ} 23.768$, de 18 de janeiro de 1934, art. $4 .{ }^{\circ}$, de serem sindicalizados os industriarios para poderem gozar férias anuais remuneradas, em face de dispositivo perfeitamente identico ao citado art. 137, letra $\mathrm{f}$, da Constituição de 1937, qual seja o do art. 121 , § $1 .^{\circ}$, letra $f$, da Constituição de 1934. Afirmou então a nossa mais alta Côrte de Justiça, pela palavra do eminente Sr. Ministro CosTA Manso: "A Constituição de 1934, no art. $121, \S 1 .^{\circ}$, letra $f$. assegurou dêsde a sua vigencia (o grifo é nosso), "férias anuais remuneradas" aos trabalhadores. Não distinguiu os sindicalizados dos não sindicalizados. Ficaram, portanto, sem efeito os dispositivos legais, que, para estimular a sindicalização estabeleceram tais distinções" (o grifo é nosso) (13).

(13) Acordão de 9 de maio de 1938, in Legislação do Trabalho, 1938, pg. 490, e Revista do Trabalho, n. ${ }^{a}$ de setembro de 1938, pg. 387. No mesmo sentido outro acordão da mesma data e constante da primeira Revista, pg. 432, e a decisão do $\mathrm{Sr}$. Ministro do Trabalho, no Boletim do Ministerio do Trabalho, n. ${ }^{\circ} 65$, de janeiro de 1940, pg. 392. Esta interpretação foi confirmada autenticamente pelo decreto-lei n. 505 , de 16 de junho que estendeu aos empregados das seç̧ões industriais das usinas de assucar, alcool e aguardente, excetuados os trabalhadores agricolas, as leis trabalhistas vigentes nas industrias, cujo art. $2 .^{\circ}$ determinou: "o direito a ferias 
Corroborando esta afirmação poderiamos citar tambem o acordão do Tribunal de Apelação de São Paulo, que decidiu haver a Constituição revogado exigencia identica de sindicalização para que os empregados pudessem recorrer ás Juntas de Conciliação e Julgamento, exigencia esta constante do art. $1 .^{\circ}$, do decreto $n .^{\circ} 22.132$, de 25 de novembro de 1932: “A objeção de que a lei n. ${ }^{\circ} 22.132$, só se refere a empregados sindicalizados e que, portanto, as Juntas só poderão conhecer das questões movidas por tais empregados improcede, pois o texto constitucional, que creou a Justiça do Trabalho e que é, portanto, a fonte de vida do Dec. Lei n. ${ }^{\circ} 39$, não estabeleceu restrição alguma quanto aos favorecidos pelas leis trabalhistas e não poderia estabelece-la, pois si tal fizesse, iria contra um dos mais importantes principios nela consagrados - a igualdade de todos perante a lei. "Não ha privilegiados por motivo de nascimento, classe social e outros" diz a Constituição. As Constituições de 1934 e 1937 expurgaram da lei 22.132, o defeito do reconhecimento de certa prerrogativa a determinada classe social" (14).

Que significam estas decisões sinão o reconhecimento de preceitos identicos ao da citada letra $f$, do art. 137, da Constituição de 1937, como regras juridicas bastantes em si?

Aliás, poderiamos demonstrar por outra forma o carater de regra juridica auto-aplicavel do discutido inciso constitucional. Bastaria lembrar com o Prof. Percival de OliveIRA que: "Os dispositivos constitucionais dependem de lei ordinaria que os disciplinem quando estabelecem principio novo, que não possa ser automaticamente executado, ou quando modificam os existentes. Não assim quando se limitam a consagrar o que já dispunham leis ordinarias (15)" Observaremos, porem, que a afirmação é menos certa quanto

será assegurado mesmo que o empregado não seja sindicalizado" Em sentido contrario: o acordão do Supremo Tribunal Federal de 21/1/38, na Revista do Trabalho, n. ${ }^{\circ}$ de agosto de 1938, pg. 356.

(14) Acordão do Tribunal Pleno, in Legislação do Trabalho, São Paulo, 1939, pg. 23.

(15) Direito e Justiça, artigo publicado no "Estado de São Paulo" edição de 7/7/40. 
aos dispositivos que modificam os existentes, justamente como ocorre na especie examinada.

Com efeito, já a Constituição de 1934, dispunha no art. 121, § 1..$^{\circ}$ letra $g$ : “A legislação do trabalho observará os seguintes preceitos, alem de outros que colimem melhorar as condições do trabalhador: indenização ao trabalhador dispensado sem justa causa" Este preceito era relativamente novo, porquanto a generalidade dos empregados não gozava ainda dessa indenização, até então existente em relação aos empregados das empresas de serviços publicos e aos bancarios, sob a forma de estabilidade no emprego. A sua extensão a todos os empregados do comercio e aos da industria, stricto sensu, foí regulamentada pela lei n. ${ }^{\circ} 62$, de 1935, que estabeleceu no art. $5 .^{\circ}$, a lista das justas causas de despedida, nelas incluindo a fôrça maior e considerando tal a supressão do emprego ou cargo $\left(\S 1 .^{\circ}\right)$, o fechamento do estabelecimento ou da filial ou a supressão de um determinado ramo de negocio $\left(\S 2 .^{\circ}\right)$ e o factum principis $\left(\S 3 .^{\circ}\right)$. Pois bem. A Constituição de 1937, no art. 137, letra $f$, estendeu a concessão da indenização a todos os casos da cessação das relações de trabalho e não somente aos de despedida injusta, modificando assim a lei anterior, sem deixar de ser auto-aplicavel o dispositivo, visto como já estava regulamentado, não subsistindo a regulamentação, em face do art. 183 da mesma Constituição, apenas naquilo que contrariasse a Constituição, explicita ou implicitamente.

Oliverra Filho argumenta com os casos possiveis de cessação do trabalho, enumerando os seguintes: acidente do trabalho, velhice, invalidez, morte natural, fechamento do estabelecimento ou da filial e factum principis. Lembrando que o art. 137, letra $f$, da Constituição, não especifica o responsavel pela indenização, concede que em todos os casos, exceção feita do fechamento do estabelecimento ou da filial, a indenização é paga: pelo empregador ou companhia de seguros, no caso de acidente; pelos Institutos de Previdencia Social, ou pelo Estado, nos demais. Quanto aos excluidos, afirma: "Não nos compete neste passo apontar quem. 
deva corresponder com a indenização criada pela Constituição a favôr do empregado, diante do $\S 2 .^{\circ}$, do art. $5 .^{\circ}$, da lei n. ${ }^{\circ} 62$, insinuando porem, que deve ser o Estado. Concorda, portanto, que o dispositivo constitucional já está regulamentado, menos quanto - a seu vêr — no caso do citado $\S 2 .^{\circ}$. Ora bem, nós afirmamos que este caso mesmo já está regulamentado. Sinão vejamos.

A supressão do emprego ou cargo ou determinado ramo de negocio e o fechamento do estabelecimento ou filial, provêm ou de fôrça maior: destruição do estabelecimento em virtude de inundação, incendio, raio, guerra, do factum principis, ou da vontade do empregador. No primeiro caso, a fôrça maior existente exclúe toda e qualquer responsabilidade do empregador, de acordo com a regra universal do direito das obrigações, consagrada no art. 1.058, do Codigo Civil e em todas as legislações, desde o Corpus Juris Civilis, até o modernissimo Codigo Suisso das Obrigações, art. 103. No segundo, o empregador deve responder pela indenização, mesmo em falta de culpa sua, em virtude do principio do risco profissional, mais ou menos aceito pela nossa legislação em materia de rescisão do contrato de trabalho, conforme já haviamos acentuado noutro lugar: "Embora reconheçamos com Barassi que uma unica destas teorias seja insuficiente para explicar todos os aspectos do problema, concordamos em que a teoria que melhor explica maior numero é exatamente a citada teoria do risco, mesmo tendo-se em vista a definição de empregador do art. $4 .^{\circ}$, do decreto n. ${ }^{\circ} 24.637$, de 1934: "Empregador é a pessoa natural ou juridica sob a responsabilidade de quem trabalha o empregado" (16)

Logo, em face do art. 137, letra $f$, da Constituição de 1937 e do art. $5 .^{\circ}$, da lei n. ${ }^{\circ} 62$, de 1935 , desde que o empregador não possa alegar que a cessação das relações de tra-

(16) Citado Direito Social Brasileiro, pg. 438. 
balho resulta: a) de fato do empregado; (17) b) de justa causa; c) de fôrça maior, responderá êle pela indenização. Assim sendo, o citado inciso constitucional revogou os $\S \S 1 .^{\circ}$ e $2 .^{\circ}$ do referido art. $5 .^{\circ}$, quando os fatos neles previstos não resultarem de fôrça maior (ou caso fortuito), no seu conceito exato, isto é; "o fato necessario cujos efeitos não era possivel evitar ou impedir" Prevalece o $\S 3 .^{\circ}$ do mesmo artigo, por isso que o factum principis, dada a sua inevitabilidade, é evidentemente um caso de fôrça maior.

6 - Refutadas assim as opiniões dos partidarios da $2 .^{a}$ tése, estão, ipso facto, sustentadas as dos Srs. Consultor Geral da Republica e Consultor do Ministerio do Trabalho.

Já salientamos que elas não excluem - como não poderiam mesmo excluir, visto como ad impossibilia nemo tenetur (18) — os casos de legitima fôrça maior. Excluem apenas as hipoteses de "maquinações ou embustes" contra o empregado, como aquela de que dá noticia recente acordão, em que a empresa alegava má situação financeira para justificar a despedida do empregado, enquanto o seu proprio Conselho Fiscal desmentia essa afirmação.

7 - Insistindo, diremos que o art. 137, letra $f$, da Constituição de 1937 , não revogou o $\S 3 .^{\circ}$, do art. $5 .^{\circ}$, da lei n. ${ }^{\circ}$ 62 , de 1935, por isso que o factum principis é um caso de fôrça maior, uniformemente reconhecido por todos os tratadistas de Direito do Trabalho. Assim, além dos autores ci-

(17) A morte, a invalidez, a velhice e até certo ponto, o acidente do trabalho são "fatos" do empregado (note-se bem que dizemos "fatos" e não "atos") e por isso não acarretam a inteira responsabilidade do empregador, visto como o empregado, direta ou indiretamente, lhes deu motivo e a Constituição no inciso citado fala em "cessação das relações de trabalho a que o trabalhador não haja dado motivo" Acarretam, entretanto, uma responsabilidade parcial: indenização transacional nos casos de acidente do trabalho e contribuição para os seguros sociais nos demais casos.

(18) Cf., abundando nos mesmos argumentos o esplendido artigo do Dr. Dorval De Lacerda, $O$ art. ${ }^{\circ} 137$ da Constituição de novembro, em I. A. P. C., n. ${ }^{\circ}$ de agosto de 1939, pg. 53. Aí tambem um artigo de João Cabral, A lei 62 e a Constituição, á pg. 54. 
tados (vide supra n. ${ }^{\circ}$, nota 2), podemos alinhar mais algumas valiosas opiniões a respeito. PAUL PIC considera casos de fôrça maior, entre outros: "o fechamento por ordem da autoridade publica, do estabelecimento industrial. Entretanto, si este fechamento for a consequencia de uma contravenção (ex.: estabelecimento perigoso, aberto sem autorização), não haveria mais fôrça maior: o fechamento sendo consecutivo á culpa do patrão, este deveria indenizar aos operarios", e, principalmente nesta hipótese: "a modificação imposta a certas clausulas essenciais do contrato por efeito de uma lei nova" (19). Da mesma opinião é Bовтоцотто: "Ocorre tambem o caso de fôrça maior, quando, por superveniente disposição de lei, a prestação do empregado se torne impossivel, em virtude de proibição imposta ao empregador de exercitar um dado ramo de atividade. O caso de fechamento da industria por ordem da autoridade é um fato que determina a resolução da relação de trabalho ou de emprego, quando, em seguida á determinação, o fechamento tenha carater definitivo. Quando tiver carater temporario, haverá apenas interrupção da relação de trabalho" (20) Peretti-griva doutrina: "Por fôrça maior deve, pois, entender-se qualquer acontecimento exterior imprevisto e normalmente imprevisivel, que aja independentemente da vontade ou da culpa da parte, e ao qual não é dado prover, seja para fazer com que não aconteça, seja para impedir-lhe as consequencias" (21) E em nota exemplifica com a revogação de uma concessão administrativa, combatendo a tése de Petracconi de que essa revogação sendo co-natural á concessão não constitue evento imprevisivel que possa incluir-se na noção de fôrça maior, para concluir: "Não deve poder bastar a previsibilidade de uma possibilidade remota e absolutamente indeterminavel a priori no

(19) Traité Elementaire de Législation Industrielle, Paris, 1930, pgs. 836 e 837 .

(20) Diritto del Lavoro, Milão, 1935, pg. 392.

(21) Il Rapporto di Impiego Privato, Milão, 1935, pg. 402 e nota 1. 
dies, para excluir a aplicabilidade da fôrça maior" Assim tambem pensam os civilistas. O Prof. Roberto de Ruggiero, por exemplo, ensina: "Mas, si se recorre ás expressões que as fontes romanas empregam para designar os casos de fôrça maior ("vis cui resisti non potest" "casus quibus resisti non potest”), o criterio distintivo parece ser o da sua irresistibilidade. Eles são eventos naturais (por exemplo: incendio, naufragio, terremoto) ou fatos de terceiro (por ex. guerra, movimentos revolucionarios, ato do soberano) que não sómente não se podem absolutamente prevêr, mas não se podem nem mesmo evitar de modo algum" (22). Da mesma forma JossERAND: "A fôrça maior será constituida pela tempestade, a inundação, uma tromba d'agua, o estado de guerra, a invasão, o banditismo, a revolução, o motim, o fato do principe, isto é, a ordem da autoridade legitima e tambem o fato de terceiros, como si um veiculo se lança sobre outro e fere ou mata os ocupantes deste" (23).

(22) Istituzioni di Diritto Privato, Messina, 1939, pg. 491.

(23) Cours de Droit Civil Positif Français, Paris, 1939, vol. II, pg. 220. Cf. Bonnecase, Précis de Droit Civil, Paris, 1934, vol. II, pg. 344 e Venzi, Diritto Civile Italiano, Turim, 1937, pg. 185, n. 203. 